\title{
$\mathrm{LDA}$ 기반 은닉 토픽 추론을 이용한 TV 프로그램 자동 추천
}

\author{
김 은 희 ${ }^{a)}$ 표 신 지 ${ }^{\mathrm{b})}$, 김 문 철a)
}

\section{Automatic TV Program Recommendation using LDA based Latent Topic Inference}

\author{
Eunhui $\mathrm{Kim}^{\mathrm{a})}$, Shinjee Pyo ${ }^{\mathrm{b})}$, and Munchurl $\mathrm{Kim}^{\mathrm{a}}{ }^{\ddagger}$ \\ 요 약
}

다채널 TV, IPTV 및 Smart TV 서비스의 등장으로 인해 수많은 방송 채널과 방대한 TV 프로그램 콘텐츠가 시청자 단말로 제공됨으 로써 시청자들은 자신이 원하는 콘텐츠를 쉽게 찾고 소비하는 것이 어려운 TV 시청 환경을 맞게 되었다. 따라서 TV 사용자들에게 자신 이 선호하는 콘텐츠를 자동 추천해 줌으로써 원하는 콘텐츠로의 접근성을 증대시키는 것은 미래의 지능형 TV 서비스에 있어서 주요한 이슈이다. 이에 본 논문에서는 사용자의 선호 취향과 대중의 선호취향을 모두 고려한 협업필터링 개념의 통계적 기계학습 기반 TV 프로 그램 추천 모델을 제시한다. 이를 위해 시청한 TV 콘텐츠에 대한 선호 토픽을 사용자의 시청 선호도로 보고, 최근 널리 활용되고 있는 $\mathrm{LDA}$ (Latent Dirichlet Allocation)모델을 TV 프로그램 추천 모델에 적용하였다. LDA 기반 TV 프로그램 추천 성능을 개선하기 위해 본 논문에서는 $\mathrm{TV}$ 시청 이용내역 데이터를 기반으로, TV 사용자들의 관심 토픽을 은닉 변수로 하고, $\mathrm{TV}$ 사용자들의 관심 토픽에 대한 다 양성을 반영하기 위해 은닉 변수의 확률분포 특성을 비대칭 디리클레(Dirichlet) 분포로 모형화하여 실험에 적용하였다. 제안된 LDA 기 반 TV 프로그램 자동 추천 방법의 성능을 검증하기 위해, 유사 시청 특성을 갖는 사용자 그룹에 대해 상위 5 개의 $\mathrm{TV}$ 프로그램을 일주 일 단위로 추천하였을 경우 평균 $66.5 \%, 2$ 개월 단위의 추천에 대해서는 평균 $77.9 \%$ 의 precision 추천 성능을 확인할 수 있었다.

\begin{abstract}
With the advent of multi-channel TV, IPTV and smart TV services, excessive amounts of TV program contents become available at users' sides, which makes it very difficult for TV viewers to easily find and consume their preferred TV programs. Therefore, the service of automatic TV recommendation is an important issue for TV users for future intelligent TV services, which allows to improve access to their preferred TV contents. In this paper, we present a recommendation model based on statistical machine learning using a collaborative filtering concept by taking in account both public and personal preferences on TV program contents. For this, users' preference on TV programs is modeled as a latent topic variable using LDA (Latent Dirichlet Allocation) which is recently applied in various application domains. To apply LDA for TV recommendation appropriately, TV viewers's interested topics is regarded as latent topics in LDA, and asymmetric Dirichlet distribution is applied on the LDA which can reveal the diversity of the TV viewers' interests on topics based on the analysis of the real TV usage history data. The experimental results show that the proposed LDA based TV recommendation method yields average $66.5 \%$ with top 5 ranked TV programs in weekly recommendation, average $77.9 \%$ precision in bimonthly recommendation with top 5 ranked TV programs for the TV usage history data of similar taste user groups.
\end{abstract}

Keyword : Collaborative Filtering, Smart TV, Recommendation System, Latent Dirichlet Allocation, Topic Modeling

a) 한국과학기술원 전기및전자공학과

Korea Advanced Institute of Science and Technology (KAIST), Electrical Engineering

b) 한국과학기술원 정보통신공학과

Korea Advanced Institute of Science and Technology (KAIST), Information and Communications Engineering

\# 교신저자 : 김문철 (mkim@ee.kaist.ac.kr)

※본 연구는 2011년도 일부 정부(교육과학기술부)의 재원으로 한국연구재단의 기초연구사업 지원을 받아 수행된 것이고(2011-0012085), 지식경제부 및 한국 산업 기술평가 관리원의 IT산업융합원천기술개발사업의 일환으로 수행하였음. [10039161, 스마트 TV의 UX 향상을 위한 UI 핵심 기술 연구]

· 접수일(2012년1월6일), 수정일(2012년3월8일),게재확정일(2012년3월8일) 


\section{I. 서 론}

최근 다채널, 다매체, 방송과 통신의 융합으로 인한 IPTV 및 Smart TV의 등장으로 인해, 방대한 양의 TV 프 로그램이 시청자에게 제공되고 있다. 이로 인해 시청자(사 용자)가 원하는 TV 프로그램 콘텐츠를 찾아 시청하는 것 이 어려운 TV 시청환경이 되었다. ChoiceStream 조사기관 에 따르면 $75 \%$ 의 사용자들은 원하는 콘텐츠를 찾기까지 몇 분이상이 걸리며, $34 \%$ 의 고객들은 $\mathrm{TV}, \mathrm{PC}$ 및 모바일 기기에서 이러한 원하는 콘텐츠를 선택하는 것에 두려움 을 느낀다고 보고 된 바 있다 ${ }^{[1]}$. 또한, Motorola의 조사에 따르면 영국인 $50 \%$ 가 개인의 시청 경험에 맞춘 추천에 관 심을 보였으며, $43 \%$ 의 사용자는 흥미 있는 콘텐츠들이 추천될 경우, $\mathrm{VOD}$ 콘텐츠 소비를 위해 돈을 지불할 의사 가 있다고 밝힌 바 있다 ${ }^{[3]}$. 이러한 환경 속에서 사용자의 $\mathrm{TV}$ 콘텐츠 소비 욕구에 맞춰 콘텐츠를 제시하는 것은 중 요한 일이다. 따라서 본 논문에서의 사용자 선호 TV 프로 그램 콘텐츠의 자동 추천 연구는 실제 사용자의 시청 이용 내역 데이터를 기반으로 사용자를 학습하고, 사용자의 TV 프로그램 콘텐츠의 접근성 및 편리성을 향상시키는 것을 목표로 한다.

콘텐츠 추천에 대한 연구는 비디오 추천 및 음악 추천, 책 추천, 뉴스 추천과 같이 단편 판매를 목표로 둔 Amazon, Google, Apple과 같은 온라인 상점 및 검색 업체 그리고 모바일 폰의 앱 추천 등을 통해 연구되어 왔고, 그 실효성이 입증되어 왔다다지 추천은 검색과 밀접한 연관을 지니고 있 으며 키워드 중심의 query에 관련 연관 검색어들이 도출되 는 형태이다. 사용자에게 상품의 추천은 이와 유사한 형태 로 사용자의 소비 이용내역을 query에 매칭하고 관련된 콘 텐츠들을 추천해주는 형태를 일반적으로 적용해 왔다. 관 련 연구 분야에 있어서, 사용자의 선호도를 특징 벡터 (feature vector)로 표현하고, 이를 가상의 은닉 토픽(hidden topic, latent topic)에 표현한 대표적인 모델로 Hofmann의 PLSI(Probabilistic Latent Semantic Indexing) ${ }^{[4]}$ 이 있다. 이 후, 해당 모델이 데이터에 한정적으로 over-fitting되는 한계 를 극복하기 위한 Blei의 LDA(Latent Dirichlet Allocation $)^{[5]}$ 가 있다.
본 논문에서는 토픽 모델링(topic modeling)의 기본이 되 는 $\mathrm{LDA}$ 를 기반으로 TV 추천 시스템의 구성 및 추천 모델 을 제시한다. 개인의 선호도와 동시에 대중의 선호도를 고 려한 협업필터링 기반의 추천모델을 제안한다. 사용자에게 직접 TV 프로그램에 대한 선호여부를 요구하지 않고, 사용 자의 시청 이용 데이터를 기반으로 사용자 선호도를 학습 하고 이를 기반으로 사용자 선호도가 높은 TV 프로그램을 추천하는 모델을 제시한다.

모델의 주요 변수로 개인별 토픽에 대한 선호도와 각 토픽 에 대한 대중의 선호도가 있는데, 이를 각각 다항 분포로 모 델링 하였다. 개인별 추천에 있어, 대중의 선호도 보다는 개 인의 선호도 중심의 추천이 되도록 하기 위해, 상위 확률 값 을 갖는 토픽을 개인별 선호 토픽으로 고려하였다. 또한 TV 프로그램에 대한 사용자들의 시청 관심은 개인별 차이가 크 므로, 사용자 개인별 선호도가 잘 드러나도록 비대칭 디리클 레 분포(dirichlet distribution)를 학습하도록 적용하였다. 이 러한 방법으로 학습된 파라미터 기반 순위정렬모델을 이용 하여 개인별 추천을 실행하고 이에 대한 추천 성능 실험 결과 를 확인한다. 일반적으로 토픽 모델링의 결과로서 하나의 토 픽에 포함되는 상위 토픽 확률 값을 가지는 $\mathrm{TV}$ 프로그램들 은 일관된 장르나 채널에서 방영되는 TV 프로그램들로 구성 될 수 있을 뿐만 아니라, 일관된 장르나 채널로 정의되지 않 는 선호 시청 TV 프로그램 목록들로 구성되는 특성을 보인 다. TV 프로그램 추천에서의 은닉 토픽은 이에 속한 TV 프 로그램들을 시청한 사용자의 관심 토픽을 반영하는 것으로 가정할 수 있는데, 제안된 은닉 토픽 추론 기반 TV 프로그램 자동 추천 방법은 기존의 선호 장르별 및 선호 채널별로 TV 프로그램을 추천하는 방식보다 사용자들의 TV시청 선호의 다양성을 더 잘 표현할 수 있다고 볼 수 있다.

본 논문은 다음과 같이 구성되어 있다. 파장에서는 먼저 관련 연구에 대해 살펴본다. 추천 시스템 구성 및 실험에 사용한 데이터에 대해 $\Pi$ 팡에서 설명한다. 그리고 $\mathrm{IV}$ 장에서 는 디리클레분포의 특징에 대해 설명하고, 본 논문에서 추 천 모델로 활용한 Collapsed Gibbs Sampling 방법을 이용 한 LDA 모델 및 협업 필터링 기반 TV 프로그램 자동 추천 방법에 대해 설명한다. 실험 결과와 분석은 $\mathrm{V}$ 장에 제시되 어 있고 VI장에서 결론을 제시한다. 


\section{II. 관련 연구}

사용자 선호도 기반 TV 프로그램 자동 추천 연구로서 협업필터링을 $\mathrm{TV}$ 프로그램 시청 기록데이터에 적용하여 사용자 선호 프로그램을 추론한 BM(Best Match) 기반 추 천 모델이 있다 ${ }^{[12]}$. 제안된 추천 모델은 개인별 TV 콘텐츠 에 대한 순위 정렬 모델로서, 시청 기록 데이터를 학습과 검증 기간으로 나누어 추천 성능에 대해 Precision/Recall, ANMRR(Average Normalized Modified Retrieval Rank)을 측정한 실험 결과를 제시하였다. $\mathrm{BM}$ 기반 추천 모델은 $\mathrm{TV}$ 프로그램에 대해 시청 빈도 기반 협업 필터링 알고리듬 을 적용한 모델로서, 사용자들이 선호한 은닉 토픽을 관찰 할 수 없는 한계가 있다. 다시 말해, 사용자들의 시청 선호 도를 각 그룹 내 시청된 TV 프로그램들의 장르 및 채널 등 에 대한 분석은 가능하나, 이러한 분석은 추가적인 작업을 요한다.

상대적으로, 확률 기반의 은닉 토픽 모델을 이용할 경우, 각 토픽에 대해 확률 값을 선호도 수치로 이용하여 각 $\mathrm{TV}$ 프로그램에 대한 정렬이 가능하므로, 선호되는 은닉 토픽 에 대한 분석이 용이한 장점이 있다.

본 논문의 TV 프로그램 추천 모델은 Beli의 LDA 모델 [5]을 기반으로 하고 있는데, LDA는 문서 생성 모델로서 사용자가 글을 쓰는 과정을 정형화 하였다. 즉, 사용자가 글을 쓰기 위해 먼저 토픽을 선택하고, 해당 토픽에 적합한 단어를 선택하여, 몇 가지 토픽의 단락으로 구성된 글을 작 성하게 된다. 이러한 과정의 주요 변수가 되는 문서, 토픽, 단어의 토픽, 단어들을 랜덤 변수화 하여 도식 모델 (Graphical Model)의 주요 노드에 대응시켜 베이지안 모델 로 구성하였다. 본 논문에서 제안된 $\mathrm{TV}$ 프로그램 추천 모 델은 Beli의 LDA 모델을 기본으로 하는 협업 필터링 기반 의 $\mathrm{TV}$ 추천 모델이며 $\mathrm{IV}$ 장 2절에서 자세히 설명한다.

Blei는 LDA 모델을 협업 필터링에 적용한 실험을 제시 한 바 있다다. 그런데, 해당 실험에 대한 검증 데이터로서 'Each Movie dataset'을 사용 하였는데, 사용자가 직접 영 화에 대해 별점을 주어 생성된 데이터이므로 해당 데이터 내에 별점의 희박성이 크고 단편위주의 영화들로 구성되어 본 논문에서 사용한 TV 시청 데이터가 동일 제목 하에 여
러 단편들이 존재하는 TV 프로그램들이 주류를 이룬다는 점과 다르다. 또한, Blei의 실험에서 추천의 정확도를 측정 하기 위해 정의하여 사용한 perplexity는 추천 성능의 정확 도를 정량적으로 계산하는데 어려움이 있다. 반면, 본 논문 에서는 평균 precision 방법을 통해 추천 성능을 검증하였 다. Blei의 실험 방법은 대칭 디리클레 분포(symmetric Dirichlet distribution)를 사용하는 한계점이 있는 반면, 본 논문에서는 비대칭 디리클레 분포(asymmetric Dirichlet distribution)를 통해 개인 선호도의 다양성을 고려한 TV 프로그램 추천이 되도록 하였다.

Asuncion은 확률기반의 모델인 LDA에 대해 다양한 추 론 기법을 비교하였다 ${ }^{[7]}$. 즉, $\mathrm{ML}$ (maximum likelihood), MAP(maximum approximate posterior), VB(Variational Bayesian), CVB(Collapsed Variational Bayesian), CVB0 (0-order Collapsed Variational Bayesian), CGB(Collapsed Gibbs Sampling) 추론 기법을 비교 구현하였다. 특히, 하이 퍼파라미터를 최적화 시킬 경우 모든 추천 기술이 비슷한 성능을 보임을 실험 입증하였다. 그러나 대칭 디리클레 분 포의 파라미터 최적화에 국한 시킨 한계가 있다 ${ }^{[7]}$.

Wallah는 깁스 샘플링(Gibbs sampling) 기법을 이용하여 비대칭 하이퍼파라미터를 LDA모델에 최적화 시키는 방법

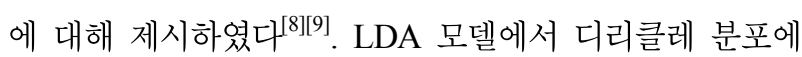
대한 파라미터의 최적 조합을 실험적으로 입증하였으며, 비대칭/대칭의 조합으로 실험하였을 경우, perplexity 기준 으로 모델 성능이 최적화됨을 확인하였다. 해당 실험을 문 서 생성 데이터를 기준으로 확인하였다 ${ }^{[12]}$.

본 논문에서는 사용자 시청 이용내역 데이터에 대해 $\mathrm{LDA}$ 모델 기반 협업 필터링 방법을 통해 TV 프로그램 추 천 모델을 제안한다. 제안된 추천모델을 통해 개인의 선호 도와 대중의 선호도를 모두 고려한 개인 사용자별 순위 정 렬 모델을 기반으로 개인에게 추천을 하되, 추천 성능 향상 을 위해 사용자 그룹의 선호도 대비 개인 선호도에 비중을 두고, 개인 선호도의 다양성을 반영하였다. 이를 위해 개인 의 선호도를 표현한 다항분포(multinomial distribution)에 서 상위 확률 값을 갖는 요소를 선별하고, 다항분포의 선행 확률 분포(prior distribution)인 디리클레 분포를 비대칭 최 적화하는 방법을 이용하였다. 


\section{III. 제안 추천 시스템}

\section{1. 제안 추천 시스템 구성 예시}

그림 1 은 본 논문에서 제안하는 은닉 토픽 추론 기반 $\mathrm{TV}$ 프로그램 자동 추천 시스템의 구성을 나타낸다. 사용자가 $\mathrm{TV}$ 프로그램 추천 서비스에 등록하면 추천서비스가 시작 된다. TV 프로그램 추천 시스템의 구성을 위해서는 추천과 직접 연관된 서버 외에 $\mathrm{TV}$ 콘텐츠 데이터베이스, TV 사용 자의 시청 기록 데이터베이스 및 TV 프로그램 콘텐츠 미디 어 스트리밍 서버(방송 송출) 등이 필요하다. 그림 2에서 추천을 주관하는 서버는 $\mathrm{TV}$ 시청자 데이터베이스, $\mathrm{TV}$ 프 로그램 콘텐츠 데이터베이스, 사용자 시청기록 데이터베이 스를 추천을 위해 이용한다.

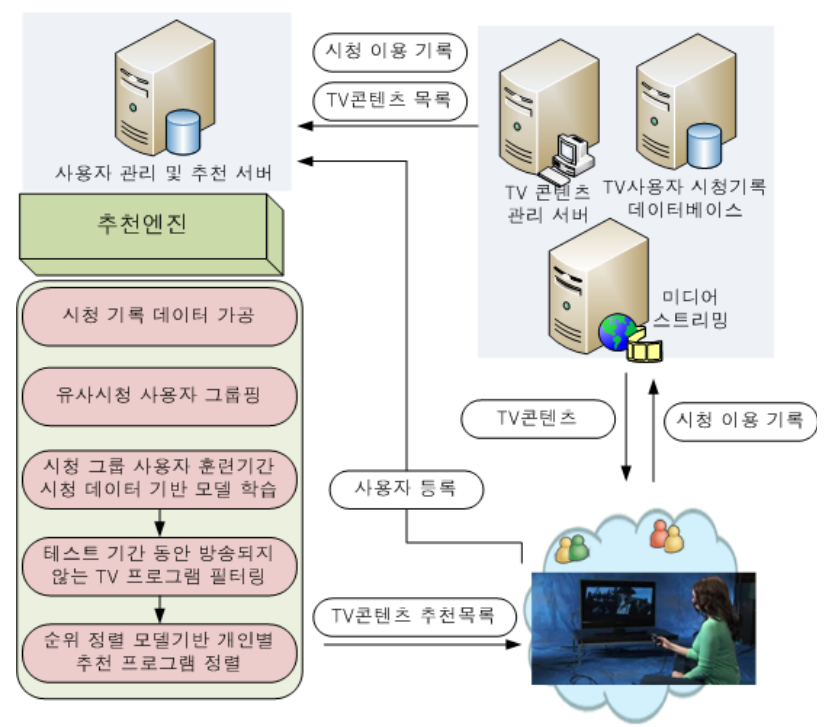

그림 1. 은닉 토픽 추론 기반 TV 프로그램 지동 추천 시스템 구성

Flg. 1. Automatic TV program recommendation system based on latent topic inference

추천 서버의 역할로는 먼저 $\mathrm{TV}$ 프로그램 시청 기록 데 이터를 기반으로 데이터에서 사용자의 선호도(사용자 profile)를 추출 및 가공한다 ${ }^{[12]}$. 사용자들의 선호도를 기반 으로 유사시청 사용자들을 그룹핑 한다. 또한, 추천 모델 의 모델 파라미터를 학습하고, $\mathrm{TV}$ 프로그램 콘텐츠 데이
터 정보를 기반으로 시청자에게 불용한 TV 프로그램 콘텐 츠를 추천 대상에서 제외시키며, 사용자 별 추천 프로그램 을 제시한다.

상대적으로 제안하는 TV 추천 시스템 구성에 있어 사용 자 기기의 기능은 사용자의 TV 시청 이용기록을 시청 기록 데이터베이스에 전달하는 역할, 추천 서버로부터 받은 TV 프로그램 콘텐츠 추천 목록을 디스플레이 기기에 맞춰 보 여주는 역할과 같이 단순화 하였다. 제안하는 추천 모델은 $\mathrm{IV}$ 장에서 자세히 설명한다.

\section{2. 실험 데이터}

실험에 사용한 데이터는 AGB Neilson Korea의 2002년 12월 1일부터 2003년 5월 31일 까지 한국 수도권 2,441명 의 사용자들을 대상으로 시청 내역을 기록한 데이터를 기 반으로 한다. 전체 사용자 중 시청 기간 안에 적어도 30 개 이상의 TV 프로그램을 시청한 사용자 1,505 명을 실험 대상 으로 사용하였다. 6 개월간 여러 회에 걸쳐 방영되는 하나의 제목하의 $\mathrm{TV}$ 프로그램을 하나의 $\mathrm{TV}$ 프로그램으로 간주하 였을 때, 전체 TV 프로그램의 개수는 1,162 개이다. 2003년 4 월 1 일을 기준으로 이전까지 4개월간의 시청 데이터를 훈 련(training) 데이터로, 이후 2개월간의 데이터를 검증(test) 데이터로 사용하였다. 또한, 검증의 정확성을 더하기 위해, 2003년 4월 1 일부터 1주일씩 4주의 검증기간 동안 30 번 이 상의 시청을 한 사용자들을 대상으로 실험 검증을 추가하 였다. 주목할 만한 TV 프로그램 콘텐츠의 특징은 6 개의 채 널을 통해 6 개월간 방영된 1,162 개의 콘텐츠 중, 500 개의 콘텐츠가 훈련기간 4 개월과 검증기간 2 개월에 걸쳐 방영되 어 콘텐츠 방영의 중복성이 높다는 데 있다.

\section{LDA 기반 제안 추천 모델}

\section{1. 디리클레 분포 (Dirichlet Distribution)}

본 논문에서 사용자의 개인 선호도를 다항분포로 표현하 고 이의 선행확률로 디리클레 분포가 정의된다. 디리클레 
분포를 다항분포의 선행확률로 두는 주된 이유는 다항 분 포내의 각 요소의 변화를 디리클레 분포의 파라미터로 표 현 가능하고, 디리클레 분포가 다항 분포의 conjugate prior 로 사후 확률이 디리클레 분포와 같은 형태의 분포가 되어 연산의 효율성을 가질 수 있는 장점이 있기 때문이다 ${ }^{[10]}$. 대 칭분포와 비대칭 분포에 따라 디리클레 분포와 다항분포와 의 관계를 그림 2에 나타내었다. 그림 2에서 색이 짙음은 데이터의 응집성이 높은 것을 의미한다.

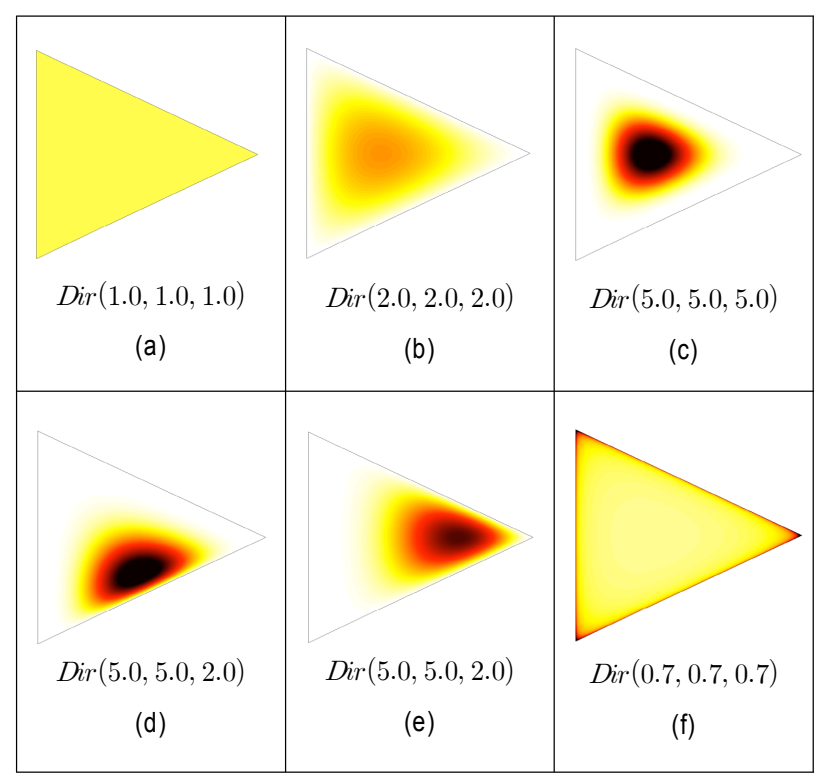

그림 2. 파라미터에 따른 디리클레분포 예시 [13]

Fig. 2. Dirichlet distribution with parameter

그림 2(a)는 파라미터 값이 모두 1 인 경우로, 균일 분포 (uniform distribution) 형태를 보인다. 또한 파라미터 값을 1 이상의 값으로 증가시킬 경우, 정규분포 모양의 형태를 보 임을 그림 2(b)와 그림 2(c)를 통해 확인할 수 있다. 대칭 파라미터가 아닌, 비대칭 파라미터 값들이 주어진 경우의 데이터 분포를 그림 2(d)와 그림 2(e)에 나타내었다. 그림 2(d)와 그림 2(e)에서 보듯이 정규 분포 형태에서 벗어나, 비대칭 형태의 데이터 분포가 드러난다. 또한, 파라미터 값 이 1 보다 작을 경우, 각 차원의 랜덤 변수에 대한 확률 값 이 결정적(deterministic) 형태를 취하게 되는데 이를 그림 2(f)를 통해 확인할 수 있다. $\theta=\left\{\theta_{1}, \theta_{2}, \cdots \theta_{K}\right\}$ 를 디리클레 분포의 파라미터 세트로 정 의하면, K-차원 디리클레 분포는 다음과 같은 수식으로 정 의된다.

$$
P\left(\theta_{1}, \theta_{2}, \cdots \theta_{K}\right)=\frac{\Gamma\left(\sum_{k} \alpha_{k}\right)}{\Pi_{k} \Gamma\left(\alpha_{k}\right)} \prod_{k=1}^{K} \theta_{k}^{\alpha_{k}-1}
$$

수식 (1)은 또한 다음과 같이 간단히 표현된다.

$$
\begin{gathered}
\theta \sim \operatorname{Dir}\left(\alpha_{1}, \alpha_{2}, \cdots, \alpha_{K}\right) \\
\operatorname{Dir}\left(\alpha_{1}, \alpha_{2}, \cdots, \alpha_{K}\right)=\operatorname{Dir}(\alpha m)
\end{gathered}
$$

특히, 수식 (3)에서 디리클레 분포는 concentration parameter $\alpha$ 와 각 차원별 변수 분포를 표현하는 vector $m\left(\sum_{k} m=1\right)$ 로 표현한 것이다.

\section{LDA의 TV 프로그램 추천 응용}

그림 3은 도식화한 $\mathrm{LDA}$ 모델을 나타낸다. 각 노드는 랜 덤 변수를 나타내고, 노드간의 선은 랜덤 변수간의 영향 관 계를, 사각형은 반복 연산과정을 나타낸다. 특히, 색이 있는 노드는 관찰된 데이터 변수를, 색이 없는 노드는 은닉 변수 를 나타낸다 ${ }^{[10]}$.

그림 3(a)은 대칭 (symmetric $\alpha$ ), 대칭(symmetric $\beta$ ) 하이 퍼파라미터 기반 LDA 모델 (SS prior LDA)을, 그림 3(b)는 비대칭(asymmetric $\alpha$ ), 대칭(symmetric $\beta$ ) 하이퍼파라미터 기반 $\mathrm{LDA}$ 모델(AS prior $\mathrm{LDA})$ 을 각각 나타낸다. 그림 3(b)에서 비대칭 $\alpha$ 디리클레 분포를 데이터를 기준으로 학 습하기 위해 디리클레 분포의 선행 확률분포로 감마분포 $(\Gamma(a, b))$ 를 정의 하였다 ${ }^{[9]}$.

$\mathrm{LDA}$ 도식 모델에서 수식 표기는 다음과 같다. $U$ 는 시청 사용자 수를 나타내고, $u_{w}$ 는 사용자 $u$ 가 시청한 $\mathrm{TV}$ 프로 그램 콘텐츠의 개수를 나타낸다. $K$ 는 전체 은닉 토픽의 개 수를 나타낸다. $V$ 는 전체 $\mathrm{TV}$ 프로그램의 개수를 의미한 다. 관찰된 데이터를 나타낸 색이 있는 노드 $w$ 는 “각 사용 자 $u$ 가 개인 선호도 $\theta_{u}$ 및 $\mathrm{TV}$ 프로그램 $w$ 의 대중 선호도 
$\phi_{w}$ 를 기반으로 시청함”을 나타낸다. 따라서 생성 모델 (generative model) 관점에서 그림 3(b)의 비대칭 LDA 기반 $\mathrm{TV}$ 프로그램 시청 모델링은 표 1 같이 설계할 수 있다.

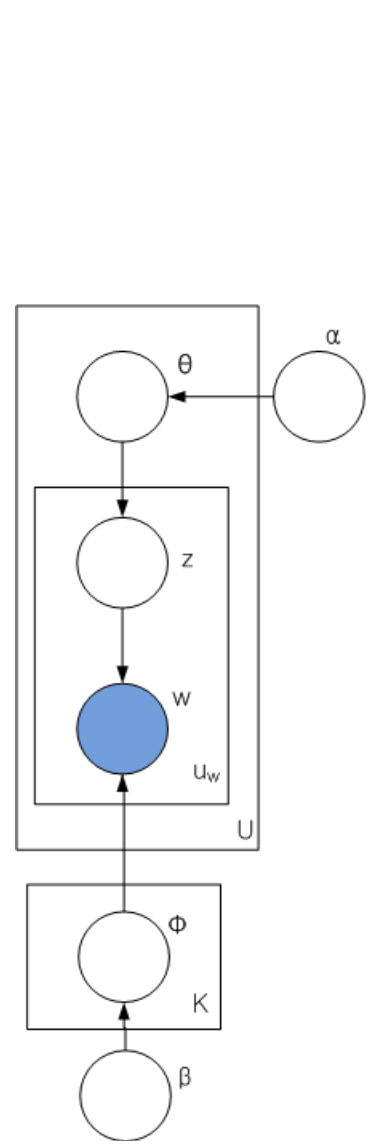

(a) 대칭 $\alpha, \beta$ LDA

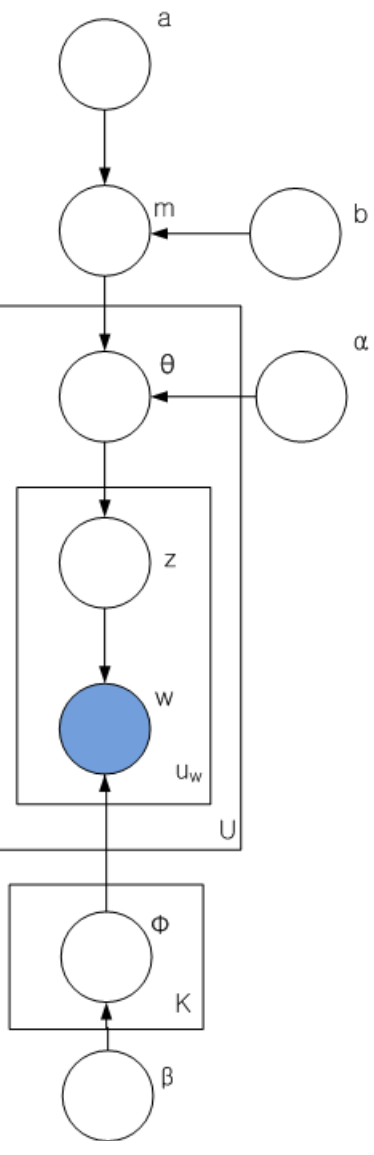

(b) 비대칭 $\alpha$,대칭 $\beta$ LDA
그림 3. LDA 도식 모델

Fig. 3. LDA Graphical Model

표 1. 비대칭 LDA 기반 TV 프로그램 시청 모델링

Table 1. 'Watching TV Program Modeling' based on LDA

\begin{tabular}{|l|cc|}
\hline $\begin{array}{l}\text { 디리클레 분포를 선행 확률로 갖는 } \\
\text { 사용자 선호도 생성 }\end{array}$ & $\theta_{u} \sim \operatorname{Dir}(\alpha m)$ & (4) \\
\hline $\begin{array}{l}\text { 디리클레 분포를 선행 확률로 갖는 각 } \\
\mathrm{TV} \text { 콘텐츠별 대중의 선호도 생성 }\end{array}$ & $\phi_{w} \sim \operatorname{Dir}(\beta)$ & (5) \\
\hline $\begin{array}{l}u \text { 사용자의 } w \text { TV프로그램에 대한 } \\
\text { 은닉 토픽 색인 }\end{array}$ & $z_{u w} \sim \operatorname{Mult}\left(\theta_{u}\right)=k$ & (6) \\
\hline $\begin{array}{l}\text { 개인의 TV콘텐츠 선호도와 대중의 } \\
\text { TV콘텐츠 선호도를 결합한 개인별 } \\
\text { TV콘텐츠 선택 }\end{array}$ & $w_{u w} \mid z_{u w}, \theta_{u w} \sim \phi_{w k} \quad$ (7) \\
\hline
\end{tabular}

\section{Collapsed Gibbs Sampling 기반 비대칭 LDA}

파장에서 설명된 바와 같이 여러 추론 기법들의 성능은 하이퍼파라미터 최적화를 통해 비슷한 성능을 보임이 입증 되었다 ${ }^{[7]}$. GS(Gibbs Sampling)은 다른 추론 기법에 비해 그 추론 과정이 상대적으로 쉽다. 또한 CGS(Collapsed Gibbs Sampling)방법은 주요 랜덤 변수를 marginalization 하여 연산하므로 랜덤변수간의 독립성 가정을 최소화 하여(변수 간의 독립성 가정은 실제 데이터특성과 맞지 않는 경향이 크다), 상대적으로 다른 추론 기법에 비해 더 정확함이 입증 되어 왔다 ${ }^{[7][16]}$. 따라서 본 논문에서는 $\mathrm{CGS}$ 기법을 추론 방 법에 사용한다.

베이지안 확률 모델은 확률 $P(w)$ 를 최대화 하는 것을 목적으로 한다. 2절의 수식들을 기준으로 $P(w)$ 는 다음과 같이 정의된다.

$$
\begin{gathered}
P(w)=P(w, z, \theta, \phi, \alpha, \beta) \\
P(w)=\sum_{z} P(w \mid z, \theta, \alpha) P(z \mid \phi, \beta) \\
P(w)=\int_{\theta} \int_{\phi} P(z, w, \theta, \phi \mid \alpha, \beta) d_{\theta} d_{\phi}
\end{gathered}
$$$$
P(z, w, \theta, \phi \mid \alpha, \beta)
$$$$
=\prod_{k=1}^{K} \prod_{u=1}^{U} \prod_{w=1}^{V} p\left(\phi_{k} \mid \beta\right) p\left(\theta_{u} \mid \alpha m_{k}\right) p\left(z_{u w} \mid \theta_{u}\right) p\left(w_{u w} \mid \phi_{k}\right)
$$

위 수식의 전개는 랜덤 변수로 지정된 $z, \theta$ 가 공존하므 로, 단순한 연산으로 해결되지 않는다. 따라서 $\mathrm{VB}$ (Variational Bayesian Inference), MCMC(Markov Chain Monte Carlo)와 같은 추론 기술을 필요로 하고 ${ }^{[5][6][7][10]}$, 본 논문에 서는 $\mathrm{MCMC}$ 방법의 하나인 $\mathrm{CGS}$ 를 사용하여 추론한다 ${ }^{[6]}$.

$\mathrm{CGS}$ 로 수식을 전개하기 위해 식(10)의 오른쪽 첫 번째 항은 $\theta$ 에 대해, 두 번째 항은 $\phi$ 에 대해 적분한다. 이 때 conjugate prior 관계에 의해 사후 확률도 디리클레 분포 형 태를 가지는 성질을 이용 한다 ${ }^{[6][8][10]}$. 두 항의 연산 결과에 대해 첫 번째 항은 $\theta$ 로서, 두 번째 항은 $\phi$ 로 표현하고, Gibbs Sampling방법을 적용하여 사용자별 각 시청 토큰( $\mathrm{IV}$ 장 4절 설명 참조)에 대해 은닉 토픽(그림 3 의 $z$ )을 샘플링 하면서 모델 파라미터 $\theta$ 와 $\phi$ 를 다음 수식과 같이 업데이트 
과정을 통해 계산한다 ${ }^{[6] 8][10]}$.

$$
\begin{gathered}
\widehat{\theta_{u k}}=\left(N_{u k}^{\sim u i}+\alpha_{k}\right) /\left(N_{\cdot u}^{\sim u i}+\sum_{k} \alpha_{k}\right) \\
\widehat{\phi_{k w}}=\left(N_{k w}^{\neg u i}+\beta_{w}\right) /\left(N_{k .}^{\urcorner u i}+\sum_{w} \beta_{w}\right)
\end{gathered}
$$

여기서 $u$ 는 사용자, $w$ 는 TV 프로그램 (전체 TV 프로 그램의 인덱스), $i$ 는 사용자의 시청 토큰, $k$ 는 은닉 토 픽 인덱스를 나타낸다. 식 (13)과 (14)에서 $\neg u i$ 는 사용자 $u$ 의 현재 시청 토큰 $i$ 를 토픽 할당 값에서 제외하는 것을 의미한다. $N_{k w}^{\sim i}$ 는 현재 TV 프로그램 $w$ 가 $k$ 토픽에 할당 된 개수이다(현재의 토픽 할당 값을 제외하는 자세한 내 용은 깁스 샘플링 알고리듬 참조 $)^{[10]} . N_{k}^{\sim u i}$ 는 $k$ 토픽에 할 당된 TV 프로그램의 개수를 의미하며, 이는 모든 $w$ 에 대해 $N_{k w}^{\sim u i}$ 를 합한 값이다. $N_{k u}^{\sim u i}$ 는 현재 사용자 $u$ 에게 $k$ 토픽이 할당된 횟수를 의미한다. $N_{. u}^{u i}$ 는 사용자 $u$ 에게 할당된 전체 토픽의 개수를 의미하며, 이는 모든 토픽 $k$ 에 대해 $N_{u k}^{\sim i}$ 를 합한 값이다 ${ }^{[6][8][9]}$. 따라서 $\widehat{\phi_{k w}}$ 는 각 $\mathrm{TV}$ 프로그램 $w$ 가 갖는 $k$ 번째 은닉 토픽에 대한 확률을 나 타내는 모델 파리미터 $\phi_{k w}$ 의 예측 치이고, $\widehat{\theta_{u k}}$ 는 각 사용 자 $u$ 의 $k$ 번째 은닉 토픽에 대한 확률을 나타내는 모델 파라미터 $\theta_{u k}$ 에 대한 예측치를 나타낸다. $\alpha$ 와 $\beta$ 는 각각 $\theta$ 와 $\phi$ 파라미터의 선행 확률 (prior)로서 디리클레 분포 이고, $\theta$ 와 $\phi$ 는 앞서 설명된 것과 같이 다항 분포이다. 일반적으로 $\alpha$ 와 $\beta$ 는 대칭(symmetric)적으로 설정된 작은 값을 사용하여왔다 ${ }^{[5][6]}$.

하이퍼파라미터를 최적화 하는 과정은 디리클레 분 포의 maximum likelihood 추정 연산을 단순한 반복적 방법(iterative scheme)으로 풀이한 Minka의 아이디어를 사용한다 ${ }^{[11]}$. Wallah는 Minka의 fixed point iteration 방 법에 대해 감마 분포의 특성을 살려 효율적인 연산이 가능한 새로운 fixed point iteration을 제안하였다 ${ }^{[8]}$. 본 논문은 비대칭 하이퍼파라미터 추정 방법으로 Wallah 가 제시한 fixed point iteration방법을 사용한다. 따라서 비대칭 디리클레 분포 파라미터 $\alpha$ 에 대한 계산식은 식 (15)와 같다.

$$
\alpha_{k}^{\prime}=\alpha_{k} \frac{\sum_{n=1}^{\max \left(N_{k n}\right)} C_{k}(n) \sum_{f=1}^{n} \frac{1}{f-1+\alpha_{k}}}{\sum_{n=1}^{\max \left(N_{u-u}\right)} C(n) \sum_{f=1}^{n} \frac{1}{f-1+\sum_{k=1}^{K} \alpha_{k}}}
$$

여기서 $C_{k}(n)$ 은 $N_{k u}$ 의 개수가 $\mathrm{n}$ 개인 개수를, $C(n)$ 은 $N_{. u}$ 의 개수가 $\mathrm{n}$ 개인 개수를 의미한다. 실험에서 사용한 깁스 샘플링 연산과정은 효율적인 샘플링을 위해 다음과 같이 세단계로 진행하였다. 먼저 burn-in 과정 후 샘플링 을 평균화하는 과정을 거친다. 샘플링을 평균화하는 과정 중에 비대칭 디리클레 분포도 식 (15)를 사용하여 동시에 학습하였다. 마지막으로 평균 샘플링 결과로 생성된 $\mathrm{z}$ 분 포를 시작으로 추론(샘플링) 과정을 추가하여 비대칭 학 습하였다.

\section{4. 제안 추천 모델}

본 논문에서는 시청 이용내역 데이터를 기반으로 각 사용자별 프로그램의 시청기준은 TV 프로그램 방영 길 이 대비 $10 \%$ 이상으로 하였고, 이를 하나의 시청 토큰으 로 간주 하였다 ${ }^{[12]}$. 훈련 기간의 시청 이용내역 데이터를 기반으로 모델을 통해 학습된 파라미터를 이용해 사용자 $u$ 의 TV 프로그램 $w$ 에 대한 점수는 식 (16)과 같이 정의 한다.

$$
\operatorname{SCore}_{u}^{w} \simeq \sum_{k=1}^{K} \log \left(1+\theta_{u k} \times \phi_{k w} \times C\right)
$$

여기서 $C$ 는 확률로 표현된 $\theta$ 와 $\phi$ 의 소수점 연산의 복잡 성을 줄이기 위해 적절히 추가된 상수이다. 추천 과정은 그 림 1에 설명된 것과 같다. 추천 성능을 고려하여 불용한 TV 프로그램 콘텐츠를 추천 항목에서 제외시켜 추천 후보 프 로그램을 구성하고, 식 (16)을 기준으로 각 사용자에게 추 천후보프로그램을 순위 정렬하여 상위에 랭크된TV 프로그 램들을 추천한다. 


\section{V. 실험 결과}

\section{1. 사용자 그룹핑}

실험에 사용한 데이터는 피장 2절에서 설명한 데이터 1,505 명의 사용자를 기반으로 한다. 먼저 실험 이전에 각 사용자들을 47 개의 장르 선호도 기준의 사용자 그룹핑을 수행하였다. 사용자 별 장르 선호도 계산은 [12] 논문을 따 른다. 그룹핑 방법은 HDP(Hierarchical Dirichlet Process) 기법 ${ }^{[14]}$ 을 Wang이 구현한 공개 소스 코드를 이용하였다 ${ }^{[15]}$

실험 결과, 사용자의 그룹별 중복성이 매우 높게 나타났 고, 86 개의 사용자 그룹을 얻었다. 첫 번째 사용자 그룹에 멤버쉽을 갖는 사용자가 981 명이었고, 이 중 첫 번째 사용 자 그룹에 최대 멤버쉽(확률 수치)을 갖는 사용자는 84명이 었다. 그룹별 멤버쉽의 중복을 허락하였을 때, 그룹별 평균 사용자 수는 628 명이었으며, 중복을 허락하지 않고 최대 멤 버쉽을 기준으로 crispy clustering(사용자별 하나의 그룹에 멤버쉽을 갖도록 그룹핑)을 고려할 경우, 멤버수가 0 이 아 닌 그룹의 개수는 42 개였고, 그룹별 평균 사용자 수는 36 명 이 되었다. 각 그룹별로 추천 모델의 파라미터를 학습하고, 그룹별 최대 멤버쉽을 갖는 사용자를 대상으로 추천 성능 을 확인하는 연산을 할 경우, 그 연산의 복잡도가 매우 높 다. 즉, 그룹핑 없이 연산하는 방법에 비해 (사용자 수 $\mathrm{N}$ 명 $\times$ (Cluster의 개수-1)) 만큼 증가하게 된다. 그리고 crispy clustering을 한 결과를 기준으로, 사용자 그룹별 연산을 하 게 될 경우, LDA 모델 특성상 멤버수가 적은 상태에서 parameter를 학습하면 일반화하는데 문제가 있어 연산의 효 용성이 떨어지게 된다. 이러한 점들을 고려하여 향후 추가 사용자 그룹핑에 대한 연구를 진행할 필요가 있다.

이후 실험은 첫 번째 사용자 그룹에 포함된 981 명의 사 용자를 대상으로 모델에 대한 파라미터를 학습하고, 학습 된 파라미터를 기준으로 추천결과에 대한 예측 치와 테스 트기간 선호 시청 결과 비교를 통해 추천모델의 성능을 검 증하였다. 전체 사용자 1,505 명을 대상으로 한 실험은 본장 의 8절에 981 명을 대상으로 한 실험과 비교 요약되어 있다. 표 4를 제외한 모든 그림 4 그림 6 과 표 2 표 3, 표 5 표 6 는 훈련기간 4 개월, 검증기간 2 개월 기준의 실험 결과이
고, 표 4 는 검증기간 1 주일씩 4 주 동안의 실험 결과이다.

\section{2. 모델 선택}

LDA 모델은 파라미터형 모델(parametric model)로서 선 행 정보로 은닉 토픽의 개수 $\mathrm{K}$ 를 지정해주어야 한다. 본 논문에서는 LDA 모델에 은닉 토픽 개수를 정함에 있어 Griffts $^{[6]}$ 에서 제시된 harmonic-likelihood의 값을 기준으로 높은 값을 갖는 토픽 개수 $(\mathrm{K})$ 를 결정 하였다. 같은 방법으 로, 각 디리클레 파라미터 $\alpha$ 와 $\beta$ 의 최적화 concentration parameter값을 harmonic-likelihood를 기준으로 grid-search 방법으로 찾았다.

주요 실험 결과는 표 2에 나타난 것과 같다. 최적화 은닉 토픽 개수 $K=200$, 각 디리클레 파라미터 $\alpha$ 와 $\beta$ 는 각각 15 와 0.05 에서 최적화된 실험결과를 보임을 확인하였다.

모델 선택 실험에서 burn-in은 2,000회, 평균 샘플링은 1,000 회를 수행하여 harmonic-likelihood 값을 비교하였다.

표 2. harmonic-likelihood기준 최적화 $K, \alpha, \beta$

Table 2. Optimization of $K, \alpha, \beta$ based on harmonic likelihood

\begin{tabular}{|c|c|c|c|}
\hline$K$ & $\alpha$ & $\beta$ & $P(w \mid K, \alpha, \beta)$ \\
\hline 20 & 100 & 0.05 & -3429763 \\
\hline 40 & 80 & 0.05 & -2573206 \\
\hline 60 & 50 & 0.05 & -2198861 \\
\hline 80 & 40 & 0.05 & -1925727 \\
\hline 200 & 15 & 0.05 & -1368198 \\
\hline
\end{tabular}

실험을 통해 $\mathrm{K}$ 값이 작을수록 $\alpha$ 값이 클 때, harmonic likelihood값이 최적화되는 것을 확인할 수 있었다. 대조적 으로, $\beta$ 값은 harmonic-likelihood 최적화에 큰 영향을 미치 지 못하는 것으로 확인되었다. 이러한 실험결과는 Wallah의 실험결과와 유사한 결과로, 최적화된 실험 결과를 얻기 위해 서는 $\alpha$ 값을 비대칭 파라미터로 최적화 하는 것이 필요한 것 과 일치한다. 상대적으로 $\beta$ 값이 1 보다 작은 값으로 설정함 으로써 각 TV 프로그램은 결정적인 토픽들로 정해질 때 모 델에 의미가 있음을 확인할 수 있었다(그림 2 참조). 


\section{3. 하이퍼-파라미터 최적화}

그림 4는 사용자의 은닉 토픽에 대한 선호도의 개인별 표준편차를 히스토그램으로 나타낸 것이다. 그림 4(a)는 비대칭 하이퍼파라미터(AS) $\alpha$, 대칭 하이퍼파라미터(SS) $\beta$ 로 학습한 결과이고, 그림 4(b)은 $\alpha, \beta$ 모두 대칭 하이퍼 파라미터로 학습한 경우이다.

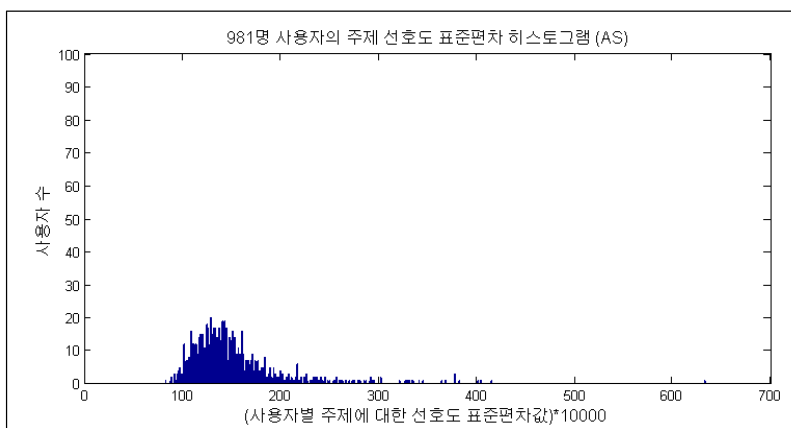

(a) 비대칭 학습 사용자 토픽 선호도 표준편차 히스토그램

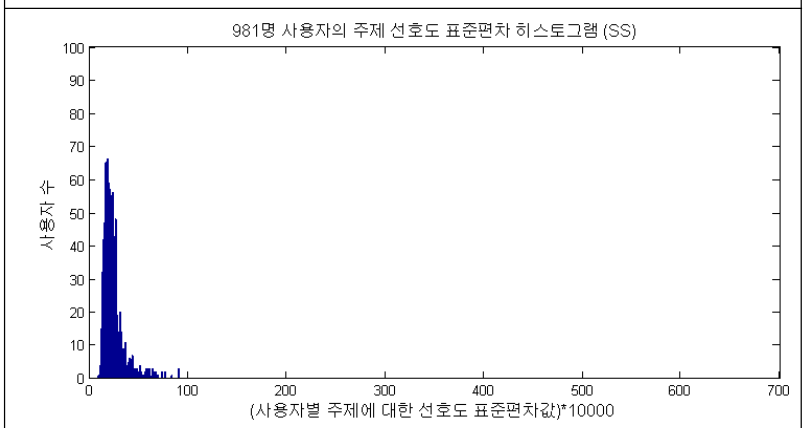

(b) 대칭 학습 사용자 토픽 선호도 표준편차 히스토그램

그림 4. 981 사용자 토픽 선호도 표준편차 히스토그램

Fig. 4. histogram of standard deviation of 981 users' preference on topics

그림 4 를 통해 확인할 수 있듯이, $\alpha$ 를 비대칭 하이퍼파 라미터로 학습할 경우, 사용자별 선호도의 분포가 흩어진 형태로 나타나 토픽에 대한 선호도가 다양함을 확인 할 수 있다. 상대적으로 대칭 하이퍼파라미터로 학습하였을 경우, 선호도의 편중을 잘 드러내지 못하고, 대부분 사용자들의 선호도 분산이 작은 값으로 치우친 결과를 보임을 확인할 수 있다.

\section{4. 사용자 프로파일 분석기반의 추천 최적화}

일반적으로 개인 TV 시청자의 사회 이슈에 대한 관심은 특정 토픽에 한정되는 경우가 있다. 예를 들어, 스포츠 열혈 팬이면서 육아에 전혀 관심이 없는 싱글남이 있을 수 있고, 패션과 육아에 관심이 크면서 스포츠에 관심이 없는 주부 가 있을 수 있다. 그런데, 그림 4 를 통해 확인하였듯이, 대 칭 디리클레 선행 분포로 학습한 사용자들의 TV 프로그램 콘텐츠에 대한 선호도의 표준 편차는 매우 낮은 값들로 집 중되어 사용자의 선호도 변화를 잘 드러내지 못하는 결과 를 보임을 확인하였다.

이와 같은 상황에서 각 개인 사용자의 토픽에 대한 선호 확률을 기준으로 상위 확률의 토픽에 대해서만 고려하도록 $\theta_{u}$ 를 변형하였다. 수식 (16)으로 정의된 개인 사용자별 콘 텐츠 순위 정렬 모델에 적용하여 상위 점수항목을 기준으 로 추천 개수를 각각 5 개, 10 개, 20 개, 30 개, 40 개로 하였을 경우, 검증 기간 동안 981 명의 사용자들의 평균 precision을 기준으로 실험 검증하였다.

그림 5 에서 보듯이, 선호 은닉 토픽을 상위 확률의 20 개 에서 40 개까지 고려하였을 경우, 추천 성능이 우수한 결과 를 보임을 확인할 수 있다. 은닉 토픽 200개를 모두 고려하 였을 경우, 40 개만 고려한 추천 성능에 비해 $20 \%$ 가 떨어진 결과를 보임을 확인할 수 있다.

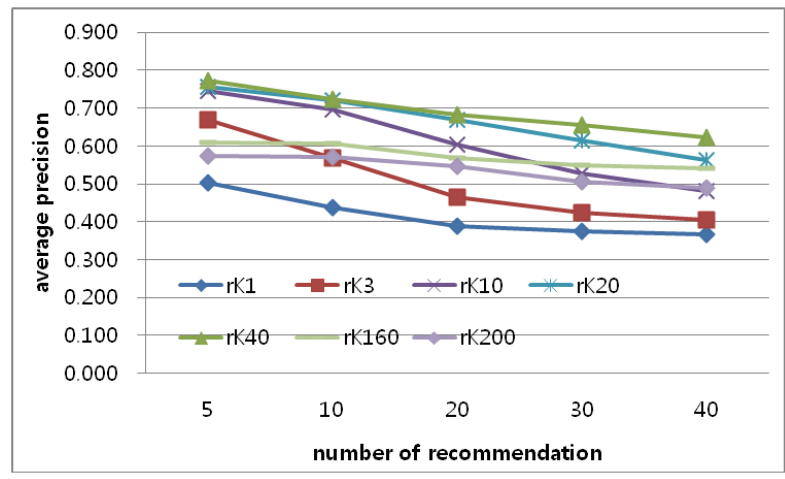

그림 5. 개인별 선호토픽 개수 한정에 따른 추천 성능 평균 precision Fig. 5. Average Precision of the recommendation with restricting the number of preference topics per user 


\section{5. 제안 추천 모델의 성능 최적화}

표 2의 실험결과를 기준으로 $\mathrm{LDA}$ 모델에 대한 각 파라 미터 값은 $K=200, \alpha=15, \beta=0.05$ 로 초기화 하였다. 단계 적으로, burn-in 과정은 2,000 회, 평균 샘플링은 1,000 회, 비 대칭 파라미터 적용 샘플링은 1 회 시행하였다.

$\alpha, \beta$ 모두 대칭 하이퍼파라미터로 학습한 경우와 $\alpha$ 는 비대칭 하이퍼파라미터, $\beta$ 는 대칭 하이퍼파라미터로 학 습한 결과와 $\mathrm{V}$ 장 4절에서 실험한 것과 같이 선호 토픽의 개수를 40 개로 한정짓는 것과 그렇지 않은 경우에 대한 4 가지 조합에 대한 실험을 표 3에 비교하였다. 대칭 하이 퍼파라미터로 학습한 추천 성능은 선호 토픽의 개수를 40 개로 한정 지을 경우 추천 성능이 향상됨을 확인할 수 있 다. 또한, 비대칭 하이퍼파라미터로 학습할 경우 추천 성 능이 향상됨을 확인할 수 있다. 최적의 성능은 비대칭 하 이퍼파라미터로 학습하면서 개인 사용자별 선호 토픽의 개수를 40 개로 한정지을 때임을 실험 결과를 통해 확인할 수 있다.

표 3. 제안 추천 모델의 성능 최적화 (Cluster 1의 981 사용자) Table 3. Proposed Recommendation Model Performance Optimization (For 981 users in Cluster 1)

\begin{tabular}{|c|c|c|c|c|c|}
\hline \multirow{2}{*}{$\begin{array}{c}\text { 추천 } \\
\text { 개수 }\end{array}$} & \multicolumn{5}{|c|}{ 평균 Precision } \\
\cline { 2 - 5 } & Top-5 & Top-10 & Top-20 & Top-30 & Top-40 \\
\hline \multicolumn{6}{|c|}{$\theta_{u}$ 의 모든 토픽을 사용한 SS선행 확률 학습 } \\
\hline & 0.573 & 0.570 & 0.547 & 0.505 & 0.488 \\
\hline \multicolumn{7}{|c|}{$\theta_{u}$ 의 상위 40 토픽을 사용한 SS 선행 확률 학습 } \\
\hline & 0.772 & 0.722 & 0.684 & 0.655 & 0.624 \\
\hline$\theta_{u}$ 의 모든 토픽을 사용한 AS선행 확률 학습 \\
\hline & 0.732 & 0.718 & 0.689 & 0.663 & 0.640 \\
\hline \multicolumn{7}{|c|}{$\theta_{u}$ 의 상위 40 토픽을 사용한 AS 선행 확률 학습 } \\
\hline & 0.779 & 0.742 & 0.703 & 0.670 & 0.639 \\
\hline
\end{tabular}

표 3은 981명의 사용자에 대한 4 개월 사용 내역 데이터 를 파라미터 훈련에 사용하였고, 그 이후의 2 개월 사용 내 역 데이터를 추천 성능 검증 데이터에 사용한 실험 결과이 다. 표 4는 4 개월 동안 981 명의 사용자에 대한 훈련 기간을
거친 파라미터를 기준으로, 981명 중 2003년 4월 1일부터 일주일의 검증 기간씩 30 번 이상 시청한 사용자를 대상으 로 4주 동안 시청 내역 기준의 평균 precision 결과이다. 실 험 검증 방법은 ' $\theta_{u}$ 의 상위 40 토픽을 사용한 $\mathrm{AS}$ 선행 확 률 학습'한 방법을 사용하였다.

표 4. 일주일 훈련 검증 기간 동안 추천 성능 검증

Table 4. Proposed Recommendation Model Performance for one week

\begin{tabular}{|c|c|c|c|c|c|c|}
\hline \multirow{2}{*}{$\begin{array}{c}\text { 사용 } \\
\text { 자수 }\end{array}$} & \multicolumn{5}{|c|}{ 평균 Precision } \\
\hline $04 / 01 ~ 04 / 07$ & 684 & 0.670 & 0.650 & 0.604 & 0.563 & 0.510 \\
\hline $04 / 08 \sim 04 / 14$ & 655 & 0.678 & 0.641 & 0.588 & 0.540 & 0.492 \\
\hline $04 / 15 \sim 04 / 21$ & 645 & 0.656 & 0.627 & 0.571 & 0.528 & 0.481 \\
\hline $04 / 22 \sim 04 / 28$ & 627 & 0.654 & 0.624 & 0.564 & 0.519 & 0.473 \\
\hline & & 0.665 & 0.636 & 0.582 & 0.537 & 0.489 \\
\hline
\end{tabular}

\section{6. 은닉 토픽 추론 실험 결과에 대한 고찰}

각 토픽에 대해 다항 분포로 표현된 $\phi_{k}$ 는 상위 확률의 $\mathrm{TV}$ 프로그램을 기준으로 데이터를 정렬하여 해당 토픽의 특성을 분석하는데 도움을 얻을 수 있다. 일반적으로 같은 방법을 통해 문서 생성 모델에서 단어의 일관성을 통해 토 픽 모델링의 의미를 찾는 시도가 있어 왔다다]6[6]. 각 토픽 별로 찾아진 TV 프로그램의 일관성을 찾기 위해 장르, 채 널, 방영 요일, 방영시간대, TV 프로그램 제목, 하위 장르에 대해 분석하였다. 방영 시간대는 2 시를 시작시간으로 하루 를 6 등분하여 4 시간 단위를 기준으로 나눈 시간대를 의미 한다.

그림 6은 200개의 토픽 중 샘플링 된 0 번 토픽과 17 번 토픽의 상위 확률 TV 프로그램 콘텐츠를 보여주고 있다. 0 번 토픽은 다큐멘터리, 뉴스, 생활정보, 시트콤 등이 포함 된 TV 프로그램들이 포함되어 있다. 17번 토픽은 만화/인 형극이 주를 이루며 오락 및 뉴스 그리고 생활정보 장르의 $\mathrm{TV}$ 프로그램이 포함되어 있다. 즉, 하나의 토픽은 사용자 


\section{Topic}

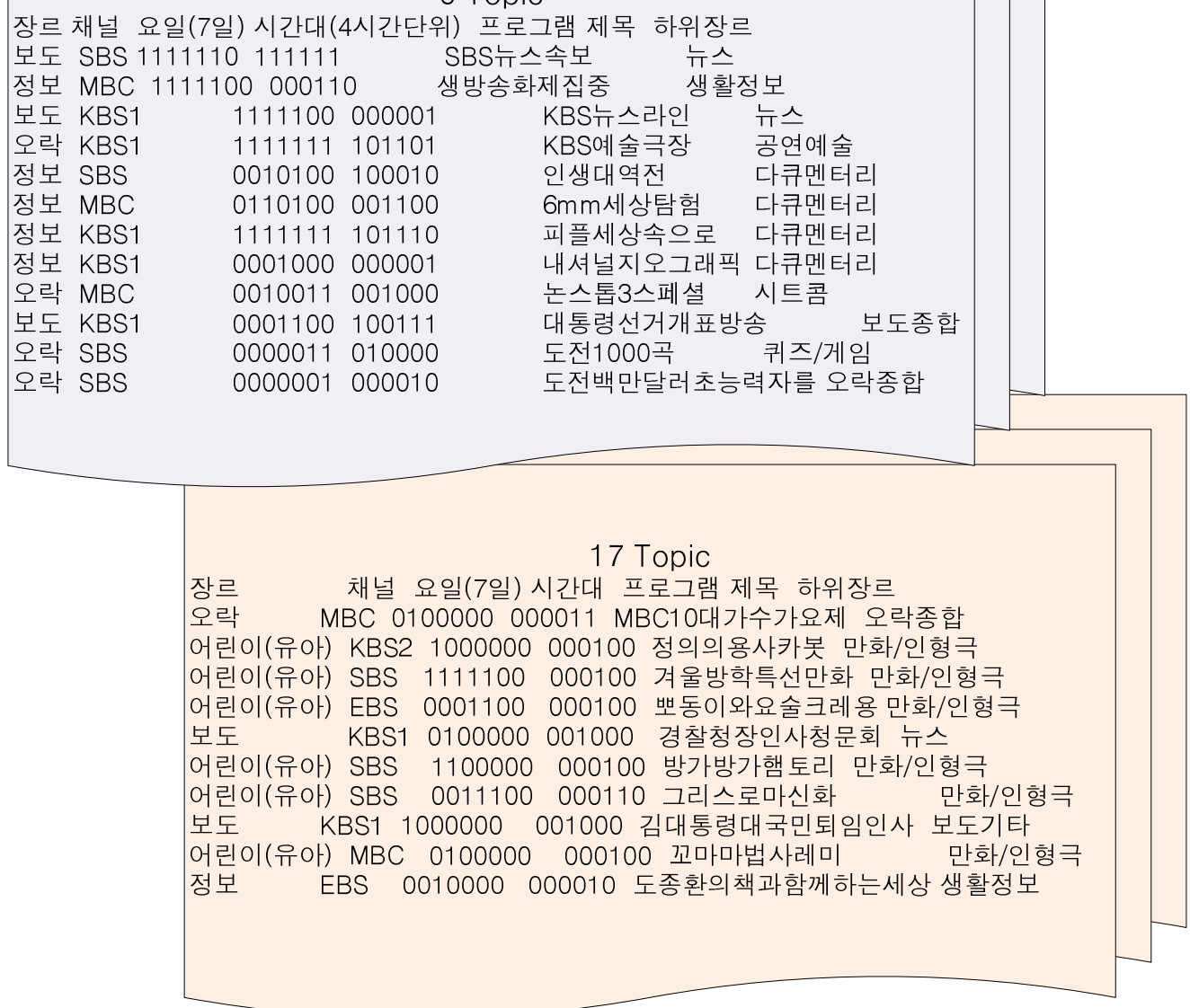

그림 6. 토픽별 상위 확률 TV프로그램 콘텐츠

Fig. 6. High Probability TV Program Contents per topic

들의 시청 사유를 드러내는 것으로 유사 시청 사용자들의 시청 사유는 하나의 일정한 장르나 채널 등의 단순한 카 테고리로 정의할 수 없는 은닉 토픽 모델을 통해 확인하 기적절한 복합적인 의미를 담고 있음을 알 수 있다. 또한, 17 번 토픽은 만화, 인형극이 주를 이루어 어린이들이 주 로 시청한 콘텐츠인 가운데 뉴스 및 생활정보 등의 $\mathrm{TV}$ 콘텐츠가 포함되어 있는 정보 등을 통해 TV시청은 개인 별 시청 보다는 가족단위의 시청이 이뤄지는 것을 짐작 할 수 있다.

\section{7. 사용자별 TV프로그램 추천 분석}

표 5는 샘플 사용자 207042201(사용자 ID)에게 제시 모 델기반으로 추천된 $\mathrm{TV}$ 프로그램의 예시이다. $\mathrm{ID}$ 는 $\mathrm{TV}$ 프로 그램의 ID를 나타내며, 적중은 5 개, 10 개, 20 개, 30 개, 40 개 의 각각의 추천에 대해 해당 추천의 개수를 통해 실제 사용 자가 시청한 $\mathrm{TV}$ 프로그램에 몇 개를 추천하였을 경우 포함 되었는지를 나타낸 정보이다. 점수는 식 (16)을 통해 나온 점수를 의미한다. 
표 5. 사용자 207042201의 추천 예시

Table. 5. Recommendation Example for user 207042201

\begin{tabular}{|c|c|c|c|c|c|c|c|c|}
\hline & \multicolumn{9}{|c|}{$\theta_{u}$ 의 상위 40 토픽을 사용한 AS 선행 확률 학습 } \\
\hline 순위 & ID & 적중 & 점수 & 채널 & 요일 & 시간대 & 제목 & 장르 \\
\hline 1 & 604 & 5 & 6.9805 & MBC & 1111101 & 001110 & 일일연속극 & 드라마 \\
\hline 2 & 1067 & 5 & 5.7086 & MBC & 1111111 & 000011 & MBC뉴스데스크 & 뉴스 \\
\hline 3 & 758 & 5 & 4.0923 & SBS & 0000011 & 001111 & 특별기획 & 드라마 \\
\hline 4 & 1068 & 5 & 3.0966 & MBC & 1111110 & 111111 & MBC뉴스속보 & 뉴스 \\
\hline 5 & 651 & 5 & 2.9944 & SBS & 0000011 & 001110 & 주말극장 & 드라마 \\
\hline 6 & 1087 & 10 & 2.8075 & MBC & 1111111 & 000011 & MBC스포츠뉴스 & 뉴스 \\
\hline 7 & 942 & 10 & 2.5242 & KBS2 & 0001010 & 001001 & 해피투게더 & 오락종합 \\
\hline 8 & 1113 & 0 & 2.2923 & SBS & 1100000 & 000011 & SBS대하드라마 & 드라마 \\
\hline 9 & 653 & 10 & 2.2588 & MBC & 0000011 & 000110 & 주말연속극 & 드라마 \\
\hline 10 & 566 & 10 & 2.2050 & KBS2 & 1100011 & 001111 & 월화드라마 & 드라마 \\
\hline 11 & 582 & 20 & 2.1861 & KBS2 & 1111100 & 001110 & 인간극장 & 다큐 \\
\hline 12 & 289 & 20 & 2.1813 & MBC & 1111011 & 001111 & 미니시리즈 & 드라마 \\
\hline 13 & 236 & 20 & 1.9945 & KBS2 & 1000010 & 001001 & 러브스토리 & 오락종합 \\
\hline 14 & 1098 & 0 & 1.8487 & SBS & 1111111 & 000011 & SBS8 뉴스 & 뉴스 \\
\hline 15 & 947 & 0 & 1.7991 & KBS2 & 1111110 & 001110 & 헬로 발바리 & 드라마 \\
\hline 16 & 1112 & 20 & 1.7947 & SBS & 0011001 & 001110 & SBS 대기획 & 드라마 \\
\hline 17 & 539 & 0 & 1.7904 & MBC & 1110100 & 000110 & 와! 멋진세상 & 생활정보 \\
\hline 18 & 600 & 0 & 1.7870 & SBS & 1111101 & 000110 & 일일 드라마 & 드라마 \\
\hline 19 & 725 & 20 & 1.7728 & MBC & 0000001 & 000011 & 타임머신 & 다큐 \\
\hline 20 & 557 & 0 & 1.7610 & MBC & 0001000 & 000010 & 우리시대 & 다큐 \\
\hline
\end{tabular}

추천 결과를 확인할 수 있듯이, 본 논문을 통해 제안된추천 은 시청 습관에 맞춘 편리한 TV프로그램의 접근에 도움이 되며, 대중의 인기 프로그램도 동시에 알 수 있는 추천이 될 수 있을 것이라 예상된다.

\section{8. 사용자 그룹핑의 중요성 및 필요성}

유사 취향 사용자 그룹핑 없이 1,505 명의 사용자 TV 프 로그램 시청 내역 데이터를 기반으로, 제안된 추천과정을 통해 추천하였을 경우의 추천 성능을 아래 표 6에 나타내었 다. grid-search 방식으로 구한 최적화 파라미터 초기 값은 $K=200, \alpha=15, \beta=0.001$ 으로 설정하였다. 실험 성능의 향
상을 위해 burn-in 샘플링, average 샘플링, 비대칭 파라미 터 적용 샘플링 횟수를 각각 4,000회, 2,000회, 1 회 시행하 였다. 표 6 을 통해 확인 할 수 있듯이, 대칭 하이퍼파라미터 기반의 추천 성능이 표 3 에 비해 향상된 결과를 보인 것을 확인할 수 있다. 이는 샘플링 횟수의 차이에 기인하며, 데이 터 량이 많아짐에 따라 전체적인 데이터가 정규분포 형태 에 가까워졌기 때문이다(그림 2 참조). 표 6 은 표 3에 비해 4 가지 서로 다른 학습 방식의 차이에 따른 추천 성능 차이 가 크지 않으며, 가장 성능이 우수한 “ $\theta_{u}$ 의 상위 40 토픽을 사용한 $\mathrm{AS}$ 선행 확률 학습” 방식에 대해 표 6의 결과가 표 3 의 결과에 비해 평균 precision 성능이 낮음을 확인할 수 있다. 이러한 차이의 원인으로는 샘플링 횟수의 차이 외에 
유사 시청 사용자에 대한 그룹핑 없이 모든 사용자의 시청 이용 내역 데이터를 사용함으로써 대중의 선호도가 지나치 게 일반화 되어 그룹의 특성을 고려한 추천에 비해 추천 성능이 떨어지는 것으로 분석된다.

표 6. 제안 추천 모델의 성능 최적화 $(1,505$ 사용자)

Table 6. Proposed Recommendation Model Performance Optimization (For 1505 users)

\begin{tabular}{|c|c|c|c|c|c|}
\hline \multirow{2}{*}{$\begin{array}{c}\text { 추천 } \\
\text { 개수 }\end{array}$} & \multicolumn{5}{|c|}{ 평균 Precision } \\
\cline { 2 - 6 } & Top-5 & Top-10 & Top-20 & Top-30 & Top-40 \\
\hline \multicolumn{7}{|c|}{$\theta_{u}$ 의 모든 토픽을 사용한 SS선행 확률 학습 } \\
\hline & 0.623 & 0.584 & 0.565 & 0.534 & 0.509 \\
\hline \multicolumn{7}{|c|}{$\theta_{u}$ 의 상위 40 토픽을 사용한 SS 선행 확률 학습 } \\
\hline & 0.647 & 0.610 & 0.563 & 0.532 & 0.508 \\
\hline & $\theta_{u}$ 의 모든 토픽을 사용한 AS선행 확률 학습 \\
\hline & 0.628 & 0.602 & 0.565 & 0.534 & 0.509 \\
\hline & $\theta_{u}$ 의 상위 40 토픽을 사용한 AS 선행 확률 학습 \\
\hline & 0.654 & 0.613 & 0.564 & 0.533 & 0.508 \\
\hline
\end{tabular}

\section{VI. 결 론}

$\mathrm{TV}$ 프로그램 시청 내역 데이터를 사용하여 은닉 토픽을 추론하고 이에 대한 협업 필터링 기술을 적용한 $\mathrm{TV}$ 프로그 램 자동 추천 방법을 제안하였다.

디리클레 분포 파라미터를 조정하여 데이터 특성을 드러 내기 위해, 비대칭 하이퍼파라미터 $\alpha$ 를 학습함으로써 각 개인 사용자별 선호도의 다양성을 드러내고, 하이퍼파라미 터 $\beta$ 를 대칭적으로 1 보다 매우 작은 값으로 설정하여 각 $\mathrm{TV}$ 프로그램이 결정적인 토픽들로 할당되도록 할 때, 추천 성능이 최적화됨을 확인 할 수 있었다. 추천 연산에 있어 개인의 선호도를 표현한 파라미터의 상위 확률 요소들을 기반으로 추천할 때 추천 성능이 향상됨을 확인할 수 있었 고, 이는 개인의 선호도가 상대적으로 대중의 선호도 보다 추천 성능에 있어 더 중요함을 제안된 검증 방법을 통해 확인하였다. 또한 유사 시청 취향 사용자들을 장르 선호도
를 기반으로 non-parametric HDP 방법을 이용하여 그룹핑 하고 이를 유사 시청 취향 사용자 그룹별 추천을 수행 하였 을 경우, 사용자 그룹핑 없이 전체 사용자를 대상으로 추천 한 것에 비해 추천 성능이 향상됨을 확인하였다. 즉, 그룹의 특성이 반영된 추천이 대중 선호도를 적절히 구성하여 추 천 성능을 향상시킴을 확인할 수 있었다.

또한 시청 사용자들의 은닉 토픽 분석을 통해 사용자들 의 시청 사유는 단순한 장르 및 채널 등으로 국한 시켜 정의 내릴 수 없는 TV 프로그램들로 구성됨을 확인할 수 있었 고, 이는 은닉 토픽 분석모델이 기존의 단순 추천 모델들에 대해 갖는 장점임을 확인하였다. TV 시청은 개인 시청 보 다는 가족 단위의 시청이 이뤄짐을 확인할 수 있었다.

향후 연구 방향으로 그룹의 선호도를 잘 드러내기 위한 연구를 진행하기 위해 정교한 클러스터링에 대한 추가 연 구와 개인의 다양한 선호도 편중을 표현할 수 있는 Matrix Factorization 기술 기반의 추천 연구 그리고 새로운 데이터 를 통한 추천의 검증연구를 진행할 예정이다.

\section{참 고 문 헌}

[1] ChoiceStream, "ChoiceStream 2007 Survey of Viewer Trends in TV and Online Video," 2007.

[2] G. Adomavicius and A. Tuzhilin, "Toward the next generation of recommender systems: A survey of the state-of-the-art and possible extensions," IEEE Trans. Knowl. Data Eng., vol. 17, no. 6, pp. 734 749,Jun. 2005.

[3] Johan De Vriendt, Natalie Degrande, Marc Verhoeyen, "Video content recommendation: An overview and discussion on technologies and business models", Bell Labs Technical Journal Special Issue: Application Enablement, Volume 16, Issue 2, pages 235-250, September 2011.

[4] T. Hofmann, Probabilistic latent semantic indexing, ACM , pp 50-57.1999.

[5] David M.Blei, Andrew Y.Ng, Michael I.Jordan, "Latent Dirichlet Allocation," Journal of Machine Learning Research 3, pp.993-1022, 2003.

[6] Tomas L. Griffiths, Mark Steyvers, "Finding scientific topics," Proceedings of the National Academy of Sciences, vol. 101, suppl. 1, pp. 5228-5235, April, 2006.

[7] A. Asuncion, M. Welling, P. Smyth, and Y. W. Teh. On smoothing and inference for topic models. In Proceedings of the International Conference on Uncertainty in Artificial Intelligence, 2009.

[8] H. M.Wallach. Structured Topic Models for Language. Ph.D. thesis, 
University of Cambridge, 2008.

[9] H. M. Wallach, D. Mimno, and A. McCallum, Rethinking lda: Why priors matter, In Advances in Neural Information Processing Systems 22, pages 1973 - 1981, 2009.

[10] C.M. Bishop. Pattern recognition and machine learning. chapter 2, 8, 10, 11, Springer, 2006.

[11] T. Minka. Estimating a Dirichlet distribution. Technical report, M.I.T., 2003.

[12] Eunhui kim, Shinjee Pyo, Eunkyung Park and Munchurl Kim, "An automatic TV Recommendation for (IP)TV Personalization," IEEE Transactions on Broadcasting, vol. 57, no.3, pp.674-684, Sept, 2011
[13] Y.W. Teh., Tutorial, An introduction to Bayesian Nonparametric Modeling, MLSS Cambridge, Sept. 2009.

[14] Y.W. Teh., M. I. Jordan, M.J. Beal, D.M. Blei. "Hierarchical dirichlet processes." Journal of the American Statistical Association 101(476): 1566-1581. 2006

[15] Chong Wang, C++ implementation of hierarchical Dirichlet process (HDP) with split-merge operations, http://www.cs.princeton.edu/ $\sim$ chongw/resource.html

[16] Y.W. Teh., D. Newman, M. Welling, "A collapsed variational bayesian inference algorithm for latent dirichlet allocation." Advances in neural information processing systems 19: 1353, 2007.

\section{저 자 소 개}

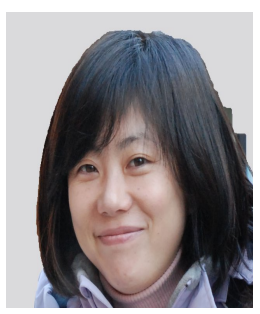

\section{김 은 희}

- 2000년 2월 : 충남대학교 정보통신공학과 공학사

- 2000년 2월 2003년 3월 : 삼성전자 Visual Display 사업부 연구원

- 2000년 3월 2007년 1월 : 삼성전자 Digital Solution Center 선임 연구원

- 2009년 2월 : 한국과학기술원, 정보통신공학과, 석사

- 2009년 3월 현재 : 한국과학기술원 전기및전자공학과 박사과정

- 주관심 분야 : 패턴인식, 통계적 학습, Recommendation Agent, Topic Modeling, Smart TV Personalization

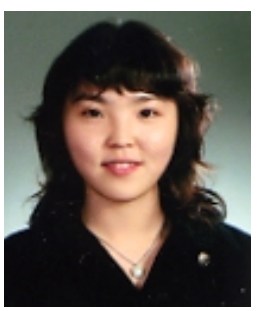

표 신 지

- 2007년 2월 : 한국정보통신대학교 전자공학과, 공학사

- 2009년 2월 : 한국과학기술원 정보통신공학과 석사

- 2009년 3월 현재 : 한국과학기술원 정보통신공학과 박사과정

- 주관심 분야 : 패턴인식, Recommendation system, Smart TV UI, Personalized IPTV service

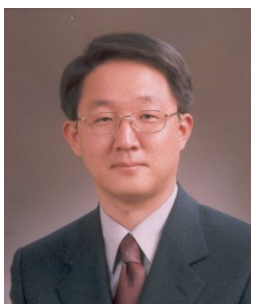

\section{김 문 철}

- 1989년 2월 : 경북대학교 전자공학과 공학사

- 1992년 12월 : University of Florida, Electrical and Computer Engineering, 석사

- 1996년 8월 : University of Florida, Electrical and Computer Engineering, 박사

- 1997년 1월 2001년 2월 : 한국전자통신연구원, 선임연구원

- 2001년 2월 2005년 8월 : 한국정보통신대학교 공학부 조교수

- 2005년 9월 2009년 2월 : 한국정보통신대학교 공학부 부교수

- 2009년 3월 현재 : 한국과학기술원 전기및전자공학과/정보통신공학과 부교수

- 주관심분야 : 비디오코딩, 패턴인식, 비주얼 정보처리, UHDTV, IPTV, UXTV, 멀티미디어 시스템 